\title{
Atypical Presentations of Bowen's Disease: A Case Series
}

\begin{abstract}
Bowen's disease (BD) is a rare premalignant condition. Classically, it presents as a well-demarcated erythematous plaque. Atypical variants in terms of the site (genitals and back) and morphology such as verrucous, hyperkeratotic, atrophic, and pigmented types are rarely described in the literature. This is the first case series of atypical presentation of $\mathrm{BD}$. We herein report five cases of $\mathrm{BD}$ diagnosed clinically and histopathologically, presenting with rare morphology over unusual sites. They were treated successfully with both medical and surgical modalities. BD can be a diagnostic challenge for a physicians as it mimics common conditions such as psoriasis and eczema. This case series is reported to bring awareness regarding such unusual presentation and sites of BD for early detection and treatment among dermatologists, thus preventing malignant transformation.
\end{abstract}

Keywords: Atypical sites, Bowen's disease, case series, premalignant condition, unusual morphology

\section{Introduction}

Bowen's disease (BD) is a rare, progressive, intraepithelial carcinoma which was first described by John Bowen in 1912.[1] The risk of development of invasive carcinoma is $3 \%-5 \%$ in extragenital lesions and $10 \%$ in genital lesions. ${ }^{[2]}$ It commonly occurs over sun-exposed areas such as head and neck and lower limbs. Clinically, it presents as solitary well-demarcated erythematous plaques mimicking psoriasis, but multiple lesions have been reported in $10 \%-20 \%$ of patients, especially with arsenic exposure. ${ }^{[1,2]}$ Uncommon clinical variants are verrucous, hyperkeratotic, and rarely pigmented variant. Generalised lesions all over the body without history of arsenic exposure and presentation on unusual sites such as fingers and genitalia have rarely been described in the literature. Here, we report a case series of five patients of $\mathrm{BD}$ with atypical morphologies over rare sites within 1-year period.

\section{Case Report}

During the last year, we came across five cases of BD indicating its increased prevalence in the Indian population. Demographic details, duration of disease, occupational status, and sun exposure are discussed in Table 1. There were no predisposing factors or history of arsenic

This is an open access journal, and articles are distributed under the terms of the Creative Commons Attribution-NonCommercial-ShareAlike 4.0 License, which allows others to remix, tweak, and build upon the work non-commercially, as long as appropriate credit is given and the new creations are licensed under the identical terms.

For reprints contact: WKHLRPMedknow_reprints@wolterskluwer.com exposure in any of the cases. Among five cases, four cases presented with solitary lesions over the finger, back, inner aspect of the thigh, and glans penis. Only one case had multiple lesions with widespread distribution involving both photo-exposed and photo-covered parts. Similarly, two of these cases were having classical psoriasiform lesions and three cases presented with unusual pigmented variety.

On clinical examination, Cases 1 and 2 presented with a well- to ill-defined skin-colored to brownish plaque of size $1.5 \mathrm{~cm} \times 1 \mathrm{~cm}$ with surface crusting on the outer aspect of the fourth finger of the right hand [Figure 1a] and well-defined erythematous plaque of size $3 \mathrm{~cm} \times$ $2 \mathrm{~cm}$ with pigmentation and crusting at periphery over the lower back [Figure 1b], respectively. Similarly, Case 3 and Case 4 presented with hyperkeratotic pigmented plaques with erosions on center and a variable degree of erythema over the glans [Figure 1c] and inner aspect of the right thigh [Figure 1d], respectively. Case 5 had multiple hyperpigmented to erythematous plaques with scaling and crusting of size ranging from $0.5 \mathrm{~cm} \times 2 \mathrm{~cm}$ to $4 \mathrm{~cm} \times 6$ $\mathrm{cm}$ widespread distribution [Figure 2]. Other systemic examinations revealed no abnormality. There was no palmoplantar keratoderma or nail abnormality, suggesting arsenic exposure. Routine investigations including complete blood count, liver

How to cite this article: Sirka CS, Sahu K, Dash G, Pradhan S, Rout AN. Atypical presentations of Bowen's disease: A case series. Indian J Med Paediatr Oncol 2020;41:926-8.

\section{Chandra Sekhar Sirka ${ }^{1}$, Kananbala Sahu ${ }^{1}$, Gaurav Dash', Swetalina Pradhan², Arpita Nibedita Rout ${ }^{1}$}

${ }^{1}$ Department of Dermatology, All India Institute of Medical Sciences, Bhubaneswar, Odisha, India, ${ }^{2}$ Department of Dermatology, All India Institute of Medical Sciences, Patna, Bihar, India

Submitted: 29-Jul-2020 Accepted in Revised Form: 02-Oct-2020

Published: $31-$ Dec-2020

Address for correspondence: Dr. Kananbala Sahu, Department of Dermatology, All India Institute of Medical Sciences, Bhubaneswar, Odisha, India.

E-mail: kanansahu1987@gmail. com

Access this article online Website: www.ijmpo.org DOI: 10.4103/ijmpo.ijmpo_366_20 Quick Response Code:

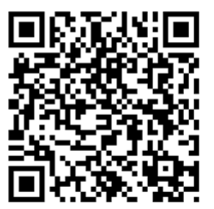




\begin{tabular}{lclcllll}
\hline \multicolumn{7}{c}{ Table 1: Demographic details of cases } \\
\hline Serial number & Age (years) & Sex & Duration & Occupation & Sun exposure & Arsenic exposure & Prior HPV infection \\
\hline Case 1 & 57 & Female & 1 year & Housewife & No & No & No \\
Case 2 & 65 & Male & 3 years & Teacher & No & No & No \\
Case 3 & 71 & Male & 6 months & Farmer & Yes & No & No \\
Case 4 & 38 & Female & 1 year & Housewife & No & No & No \\
Case 5 & 60 & Male & 8 months & Farmer & Yes & \\
\hline
\end{tabular}

HPV: Human papillomavirus

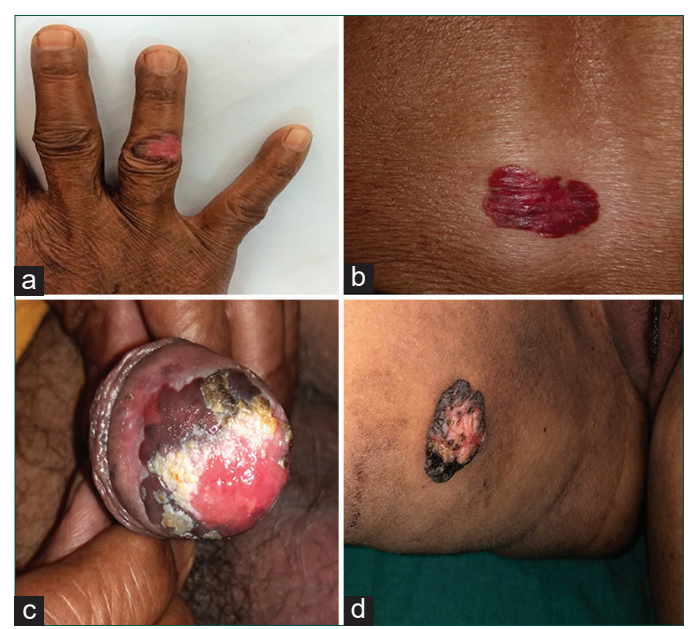

Figure 1: (a) Erythematous plaque with pigmented border with crusting over the outer aspect of the fourth finger of the right hand. (b) Erythematous plaque with crusting over the lower back. (c) Hyperkeratotic pigmented plaque with erosion on center over the glans penis. (d) Hyperkeratotic pigmented plaque with ulceration on the inner aspect of the right thigh

function test, renal function test, serology for hepatitis B, $\mathrm{HIV}$, and hepatitis $\mathrm{C}$ were in normal limits in all cases. Histopathological examinations in common showed that the cells were in complete architectural disarray, throughout the epidermis reflecting a "windblown" appearance with loss of polarity and few mitotic figures [Figure 3a]. The dyskeratotic cells were large and round with homogeneous strongly eosinophilic cytoplasm and hyperchromatic nuclei. The basement membrane and dermis were intact [Figure 3b].

They were successfully treated with topical 5\% imiquimod cream in three cases for 12 weeks, following which there was complete subsidence of lesion. Two cases initially treated with imiquimod but later subjected to elliptical excision because of partial improvement.

\section{Discussion}

$\mathrm{BD}$ is a form of intraepidermal squamous cell carcinoma in situ with a small potential of invasive malignancy. ${ }^{[1]}$ It may affect both skin and/or mucosa. The incidence is around 1.42 per 1000 population. ${ }^{[3]} \mathrm{BD}$ is uncommon among type V Fitzpatrick skin people. ${ }^{[4,5]}$ However, we have reported these five cases within 1 year, indicating their increased prevalence among Indian skin.

It can occur at any age but mostly seen in the elderly having equal sex preponderance. It usually occurs as a solitary

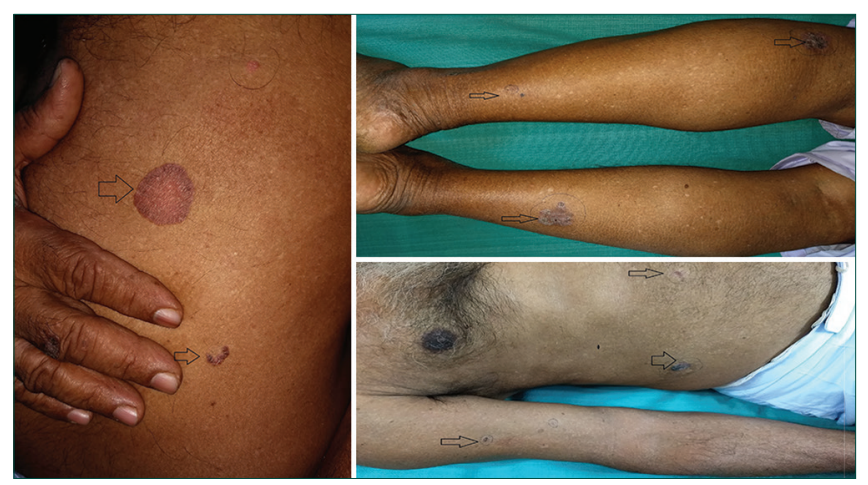

Figure 2: Hyperpigmented to erythematous plaques with scaling over the trunk and extremities

lesion over sun-exposed areas. ${ }^{[5]}$ Multiple lesions are seen in $10 \%-20 \%$ of cases with history of arsenic exposure. Case 5 had multiple lesions over both uncovered and covered areas without any history of arsenic exposure. ${ }^{[2]}$

The common sites for BD include the chronically photo-exposed sites such as head and neck and dorsum of hands and lower legs. ${ }^{[5,6]}$ Its occurrence in photo-covered sites is rare. In our case series, all patients presented with lesions on unusual sites. Our first case has lesion over the finger, the second case over the back, and the third and fourth cases presented over the penis and thigh, respectively. To the best of the author's knowledge, there was only one case report of BD presenting over the finger by Singh et al. ${ }^{[1]}$ Similarly, one case reported over the penis by Dandale et al. ${ }^{[7]}$ All our cases were misdiagnosed previously and presented late.

Clinically, BD presents as a solitary well-demarcated, erythematous, crusted, or scaly plaque. ${ }^{[1]}$ This type of morphology may be commonly confused with psoriasis, nummular eczema, actinic keratosis, bowenoid papulosis, and discoid lupus erythematosus. Other uncommon clinical variants include verrucous, hyperkeratotic, atrophic, and pigmented types. ${ }^{[1,8]}$ Among them, the pigmented variant is still very rare with $<2 \%$ incidence. ${ }^{[5,9,10]}$ In the present series, two cases presented with solitary pigmented lesion and one case presented as widespread pigmented lesions. As per the author's knowledge, there is only one case report of widespread pigmented BD by Gahalaut et $a .^{[2]}$ Furthermore, we could not explain widespread distribution in our case which is usually described with 


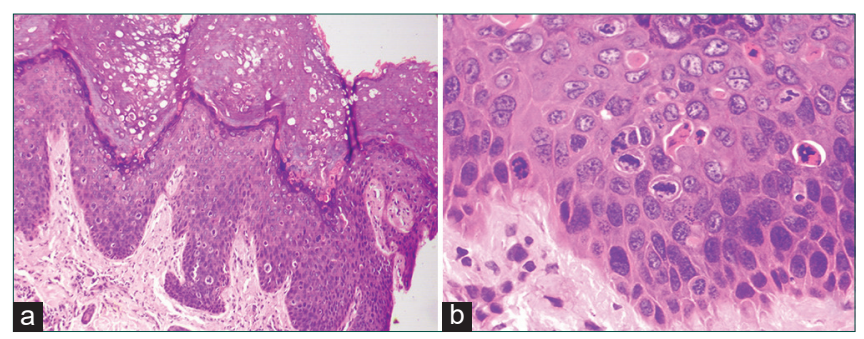

Figure 3: (a) $\mathrm{H}$ and $\mathrm{E}$ stain, $\times 10$ magnification showing architectural disarray of the epidermis. (b) $\mathrm{H}$ and $\mathrm{E}$ stain, $\times 40$ magnification showing atypical keratinocytes and frequent mitosis

arsenic exposure. The occurrence of widespread lesions in an immunocompetent individual has not been reported previously.

BD occurs on the skin damaged due to chronic ultraviolet radiation exposure, human papillomavirus infection, arsenic exposure, previous radiation, immunosuppression, trauma, and genetic factors. ${ }^{[3]}$ However, in all our cases, we did not find any predisposing factor to be correlated.

The diagnosis of BD is based on clinical suspicion and histopathology. Histological examination of $\mathrm{BD}$ reveals hyperkeratotic epidermis with a variable degree of parakeratosis. The cells throughout the epidermis lie in complete disorder resulting in a "windblown appearance" showing atypia with large hyperchromatic nuclei with intact basement membrane. ${ }^{[1]}$ In all our cases, we found cellular disarray and atypia with intact basement membrane, indicating that there was no progression toward squamous cell carcinoma.

Various treatment modalities used are topical imiquimod cream, topical 5-fluorouracil cream, cryotherapy, surgical excision, curettage and electrocautery and photodynamic therapy, lasers, and topical diclofenac. ${ }^{[1]}$ They were successfully treated with topical 5\% imiquimod cream in three cases and surgical excision in two cases.

We are reporting this case series because:

- Previously only case reports have been described and this is the first case series of BD

- Unusual presentations are less reported and easily misdiagnosed

- Our cases presented on unusual sites such as finger (second reported case), glans penis, and thigh (sun-protected sites)

- There was no evidence of immunosuppression or arsenic exposure in all cases

- Multiple pigmented variety type of presentation in one case (only one such case was reported in the literature).
Hence, a high index of suspicion, supported by histopathology, is required to diagnose and treat this condition without delay, which in turn may reduce the morbidity of patients.

\section{Declaration of patient consent}

The authors certify that they have obtained all appropriate patient consent forms. In the form the patient(s) has/have given his/her/their consent for his/her/their images and other clinical information to be reported in the journal. The patients understand that their names and initials will not be published and due efforts will be made to conceal their identity, but anonymity cannot be guaranteed.

\section{Financial support and sponsorship}

Nil.

\section{Conflicts of interest}

There are no conflicts of interest.

\section{References}

1. Singh S, Khaitan BK, Sharma MC, Seenu V, Kumawat M, Chatterjee P. Bowen's disease on finger: A diagnostic and therapeutic challenge. Indian $\mathrm{J}$ Dermatol Venereol Leprol 2013;79:227-30.

2. Gahalaut P, Rastogi MK, Mishra N, Chauhan S. Multiple pigmented Bowen's disease: A diagnostic and therapeutic dilemma. Case Rep Oncol Med 2012;2012:342030.

3. Neubert T, Lehmann P. Bowen's disease-a review of newer treatment options. Ther Clin Risk Manag 2008;4:1085-95.

4. Quinn AG, Perkins W. Non melanoma skin cancer and other epidermal skin tumours. In: Burns DA, Breathnach SM, Cox NH, Griffiths CE, editors. Rook's Textbook of Dermatology. $8^{\text {th }}$ ed.. Singapore: Wiley-Blackwell; 2010. p. 32-4.

5. Duncan KO, Geisse JK, Leffell DJ. Epithelial precancerous lesions. In: Wolff K, Goldsmith LA, Katz SI, Gilchrest BA, Paller BS, Leffell DJ, editors. Fitzpatrick's Dermatology in General Medicine. $7^{\text {th }}$ ed.. New York: Mcgraw-Hill; 2008. p. 1007-27.

6. Cox NH, Eedy DJ, Morton CA. Guidelines for management of Bowen's disease: 2006 update. Br J Dermatol 2007;156:11-21.

7. Dandale A, Mantri MD, Thakkar V, Dhurat RS, Ghate S. Bowen's disease: An unusual clinical presentation. Indian Dermatol Online J 2014;5:526-8.

8. Yahya H, Mohammed A. Bowen's disease: Report of a case in a Nigerian man. West Afr J Med 2005;24:350-1.

9. Papageorgiou PP, Koumarianou AA, Chu AC. Pigmented Bowen's disease. Br J Dermatol 1998;138:515-8.

10. Ragi G, Turner MS, Klein LE, Stoll HL Jr., Pigmented Bowen's disease and review of 420 Bowen's disease lesions. J Dermatol Surg Oncol 1988;14:765-9.

11. Gong HS, Cho JH, Roh YH, Chung MS, Baek GH. Bone invasion by squamous cell carcinoma in situ (Bowen's disease) of the finger during treatment with imiquimod 5\% cream: Case report. J Hand Surg Am 2010;35:999-1002. 